\title{
Regulation of Glutathione in Health and Disease with Special Emphasis on Chronic Alcoholism and Hyperglycaemia Mediated Liver Injury: A Brief Perspective
}

\author{
S. Mathan Kumar • Aparajita Dey
}

Received: 17 September 2013/Revised: 26 December 2013/Accepted: 27 December 2013/Published online: 10 January 2014

(C) Springer International Publishing AG 2014

\begin{abstract}
Glutathione (GSH) plays a major role in the cell due to its antioxidant properties. The transcription factor Nrf2 plays an important role in the synthesis of GSH in the cell. Increased cellular GSH content leads to greatly decreased oxidative stress and toxicity. Alcoholism and hyperglycaemia both lead to liver injury, and GSH plays a crucial role in ameliorating the hepatic damage under these pathophysiological conditions. Further, GSH transferase which is involved in drug detoxification through conjugation of xenobiotics with GSH exhibits polymorphic forms which affect its detoxification efficacy. Further, GSH supplementation through NAC and UDCA and GSH depletion through BSO and DEM lessen and aggravate cellular dysfunction, respectively. Therefore, GSH regulation which occurs through several mechanisms has a very important role in maintaining or disrupting the oxidative environment of the cell.
\end{abstract}

Keywords Glutathione - Liver - Alcoholism ·

Hyperglycaemia

\section{Introduction}

Glutathione (GSH) was first discovered in yeast cell extract and was named as 'labile hydrogen' which reduced sulphur to hydrogen sulphide [49]. Later it was revealed to have two amino acid moieties (glutamate and cysteine) and was

S. Mathan Kumar · A. Dey $(\bowtie)$

Life Science Division, AU-KBC Research Centre, MIT Campus

of Anna University, Chromepet, Chennai 600044, India

e-mail: aparajitabhu@ rediffmail.com;

aparajitadey21@gmail.com

S. Mathan Kumar

e-mail: mathanyes@gmail.com named as 'glutathione' which denotes the glutamate and thiol residues [49, 109]. Finally, the original structure of GSH was revealed as a tripeptide consisting of glutamate, cysteine and glycine [50].

\section{Physiological Role of GSH}

Glutathione is a tripeptide thiol consisting of glutamine, cysteine and glycine. The cysteine residue in GSH contributes to its reducing property. Glutathione is mainly involved in eliminating hydrogen peroxide $\left(\mathrm{H}_{2} \mathrm{O}_{2}\right)$ which is catalyzed by GSH peroxidase, thus preventing cellular lipid peroxidation (Fig. 1). During this process the reduced GSH is converted to its oxidized form (GSSG). The oxidized form is then recycled back to its reduced form (GSH) by $\mathrm{GSH}$ reductase at the cellular expense of NADPH.

\section{Glutathione Synthesis}

The transport of the precursor amino acids through different specific amino acid transporters systems: alanine, serine and cysteine preferring (ASC), cystine glutamate preferring $\left(\mathrm{X}_{\mathrm{c}}^{-}\right)$, leucine preferring $(\mathrm{L})$ and asparagine preferring $(\mathrm{N})$ is essential for GSH synthesis [7]. Among the three precursor amino acids, cysteine proves to be the rate-limiting factor for GSH synthesis since its intracellular availability is lower than the $\mathrm{Km}$ value of $\gamma$-glutamyl cysteine synthase (GCS), whereas glutamate and glycine are abundant in the cell [7, 70]. Intracellular cysteine availability is obtained either from cysteine, cystine or methionine/serine transport (transsulphuration pathway) through the involvement of any one of the above-mentioned amino acid transporters. 


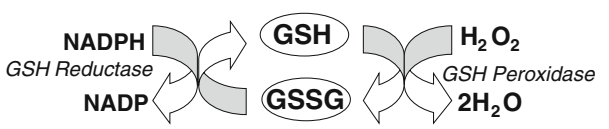

Fig. 1 Mode of action of glutathione

After cysteine is transported inside the cell, it is linked to glutamate in a distinct covalent bond which is catalyzed by the enzyme GCS, where the $\gamma$-carbon in glutamate is involved in covalent bond with the amino group of cysteine; therefore, the name $\gamma$-glutamylcysteine. The distinct covalent bond between the glutamate and the cysteine protects GSH against protease activity. GSH synthetase catalyzes the second step where glycine is added to the $\gamma$-glutamylcysteine to form GSH (Fig. 2). The GCS is regulated by feedback mechanism, i.e. the binding of GSH to its glutamate binding site inhibits the further synthesis of the enzyme [98].

\section{Regulation of GSH Synthesis: Nrf2, a Vital Player}

GSH synthesis in the cells is highly dependent on the expression and the activity of GCS. The increased GCS expression increases the intracellular GSH level. Further, the nuclear factor erythroid 2-related factor 2 (Nrf2) is involved in the regulation of GCS expression. The translocation of Nrf2 into the nucleus activates the expression of the GCS through the antioxidant response element (ARE) $[65,105]$.

Under normal physiological condition Nrf2 is bound to its negative regulator Kelch-like ECH-associated protein 1 (Keap1). When activated, Nrf2 gets released from Keap1 and is translocated to nucleus. Nrf2 signals redox changes (accumulation of GSSG) and induces GSH synthesis by activating GCS [47, 127].

The redox status of the cell is one of the factors which determine the rate of GSH synthesis by activating the $\gamma$-glutamyl cysteine expression through Nrf2 activation [105]. The increased level of reactive oxygen species (ROS) sensitizes the cell to GSH synthesis via Nrf2 signalling [29]. Nrf2induced GCS expression and increased GSH level is also regulated by insulin [62].

The activation of Nrf2 as a protective response is highly dependent on the severity of cellular toxicity [96]. Under conditions with overwhelming nitrosative stress, the signalling kinase pathway phosphoinositide-3-Kinases/v-Akt murine thymoma viral oncogene (PI3K/AKT) is involved in the activation of Nrf2 and the Nrf2-dependent genes [66].

The ethanol-induced CYP2E1 expression in the cell activates Nrf2 and increases GSH synthesis in hepatocytes [17]. The Nrf2-mediated protective response is increased under elevated CYP2E1 expression in liver cells [17]. Further, 4-hyroxynonenal (HNE), a major lipid peroxidation

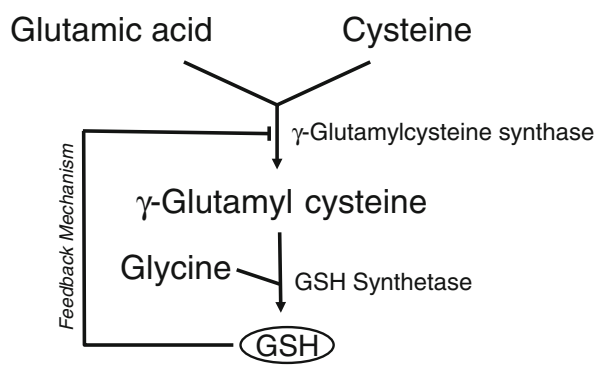

Fig. 2 Glutathione synthesis

product, induces Nrf2 signalling and the expression of GSHsynthesizing enzymes, thereby increasing the level of GSH in the cells [29].

The c-Jun NH(2)-terminal protein kinases (JNK) 1 and 2 and glycogen synthase kinase 3 alpha and 3 beta (GSK3alpha and -3beta) are the negative regulators of GSH synthesis, since their upregulation affects Nrf2 activation and the expression of $\gamma$-glutamylcysteine synthase which results in decreased GSH level [108]. On the other hand, $\mathrm{PI} 3 \mathrm{~K} / \mathrm{AKT}$ signalling is involved in the activation of Nrf2 and Nrf2-dependent genes [66] via inhibition of GSK-3beta [104].

\section{GSH and JNK Pathway}

Oxidative stress-induced altered redox potential sensitizes the cells to apoptosis by activation of the MAPK/JNK pathway [69]. The activation of the pro-apoptotic signalling pathway JNK is enhanced by GSH depletion by buthionine sulphoximine (BSO) under oxidative stress [86]. The depletion of GSH with BSO increases hydrogen peroxide in the cell and enhances JNK activation [115]. $\mathrm{N}$-acetyl cysteine (NAC), the donor for cysteine moiety of GSH prevents HNE-induced JNK activation, which suggests that GSH plays a crucial role in regulating JNK activation [115]. This is further confirmed as NAC also inhibits drug-induced JNK and ERK2 activation [60].

\section{Increased GSH Levels in the Cell: Its Beneficial Effects}

The increased GSH level by activation of the GCS subunits enhances mitochondrial stability [71]. The oxidative stressinduced caspase 3 activation and apoptosis is prevented by the increased GSH synthesis and GSH level [112]. The increase in intracellular GSH level attenuates methylglyoxal-induced toxicity [63].

The cysteine donor NAC blunts ethanol-mediated toxicity, lipid accumulation, and oxidant stress in CYP2E1overexpressing E47 cells [124]. NAC exerts, proportional to its concentration, a dual role simultaneously increasing 
both proliferation and apoptosis in HepG2 and 3B cells and interestingly, the levels of protein-bound GSH are decreased by NAC [1]. NAC treatment in rats prevents high sucrose-induced oxidative stress, as assessed by blood and tissue GSH and carbonyl levels, glucose intolerance, impaired postprandial glycemic control, and a decrease in muscle and liver insulin-induced activation of insulin receptor substrate 1 and Akt [9].

The impaired synthesis and increased loss and degradation of GSH appear to contribute to a decrease in GSH level in streptozotocin-treated diabetic rat liver [39]. NAC is able to partially protect from oxidative stress and GSH decrease, while enhancing GSH synthesis and restricting GSH loss [39].

The co-administration of NAC, Coenzyme Q10 and the SOD mimetic MnTBAP enhances the expression of mitochondrial complex I subunits, and reduces ROS production, oxidized/reduced GSH ratio, mitochondrial dysfunction and cell death induced by D-galactosamine in the cultured hepatocytes isolated from liver resections [42]. The primary hepatocytes isolated from mice lacking hepatocyte growth factor receptor c-Met (Met-KO) exhibit increased sensitivity to Fas-mediated apoptosis [40]. NAC significantly reduces Jo2-induced cell death and conversely, BSO completely abolishes the protective effects of NAC in MetKO hepatocytes [40].

UDCA reduces p53 transcriptional activity, thereby preventing its ability to induce Bax expression, mitochondrial translocation, cytochrome c release and apoptosis in primary rat hepatocytes [2]. UDCA treatment leads to a significant increase in the proliferative activity in liver histology in $40 \%$ partially hepatectomized rats [8].

UDCA inhibits both a decrease in the GSH level and an increase in the ROS in HepG2 cells exposed to excessive iron [4]. UDCA increases the gene expression of the catalytic- and modifier-units of glutamine-cysteine ligase (GCL), a key enzyme in GSH synthesis [4]. UDCA increases the GSH synthesis through the activation of the PI3K/Akt/Nrf2 pathway [4].

The pretreatment of cultured rat hepatocytes with UDCA significantly prevents the decrease in viability due to $\mathrm{H}_{2} \mathrm{O}_{2}$ or cadmium administration [77]. The amounts of GSH and protein thiol increase significantly and the mRNA levels of gamma-glutamylcysteine synthetase and metallothionein are significantly higher in UDCA-treated hepatocytes than in controls [77].

UDCA+Vitamin E improves not only aminotransferase levels and liver histology of patients with NASH, but also decreases hepatocellular apoptosis and restores circulating levels of adiponectin [6]. In liver biopsies obtained from NAFLD morbid obese patients undergoing bariatric surgery, miR-34a, apoptosis and acetylated p53 increase with disease severity, while sirtuin 1 (SIRT1) diminishes [15].
UDCA inhibits the miR-34a/SIRT1/p53 pathway in the rat liver in vivo and in primary rat hepatocytes [15].

\section{Decreased GSH Levels in the Cell: Its Injurious Effects}

The BSO-induced GSH depletion enhances mitochondrial structural aberrations by affecting the thiol redox potential, which is prevented by the overexpression of BOLA1, a mitochondrial protein [121]. The treatment of cultured mouse hepatocytes with TNF-alpha plus 0.25 or $0.5 \mathrm{mmol} /$ L DEM leads to incremental cell death in the form of apoptosis associated with increased caspase activities, release of cytochrome c, and DNA laddering [81].

Increased cell death along with increased levels of ROS and mitochondrial 3-nitrotyrosine and 4-hydroxynonenal protein adducts; and decreased mitochondrial aconitase activity and mitochondrial membrane potential are observed in HepG2 lines overexpressing CYP2E1 in mitochondria (mE10 and mE27 cells) treated with BSO as compared with cells transfected with empty vector (pCIneo) [5]. The BSO toxicity is higher in CYP2E1-expressing E47 HepG2 cells compared to the control cells [53].

The BSO treatment of HepG2 cells that causes marginal GSH deficiency increases ceruloplasmin synthesis due to increased transcription mediated by activator protein (AP)1-binding site [110]. In higher GSH deficiency ( $>40 \%$ ) with increased ROS generation, ceruloplasmin expression is decreased [110]. Thus, GSH deficiency leads to dual mechanisms in regulation of hepatic iron homoeostasis [110].

BSO treatment causes a significant reduction of the total GSH in liver $(-70 \%)$, which is attributable to the diminished levels of the reduced GSH (GSH, $-71 \%$ ) in rats [12]. The BSO-induced GSH deficiency lowers hepatic triglyceride concentrations via influencing lipogenesis [12]. The authors speculate that the reduced activity of the redox-sensitive protein tyrosine phosphatase (PTP)1B and the higher concentration of irreversible oxidized PTP1B could be, at least in part, responsible for this effect [12].

The treatment of cells expressing cytochrome P450 2E1 (CYP2E1) - E47 cells with BSO results in apoptosis as well as necrosis [124]. The activity of caspase 3 , but not caspases 1, 8, or 9, is increased in the BSO-treated E47 cells, and damage to mitochondria appears to play a role in the CYP2E1- and BSO-dependent toxicity, because mitochondrial membrane potential is found to be decreased in the process [124].

The DEM treatment of HepG2 cells causes an immediate and sustained loss of intracellular GSH, with a concomitant increase in GSSG. From 6 to $12 \mathrm{~h}$ after exposure, there is a substantial increase in the percentage of cells undergoing $\mathrm{S}$ phase arrest and apoptosis [14]. The genes 
for inhibitors of the cell cycle (CDKN1, CDKN4D and ATM) are induced, whereas cyclins (proliferating cell nuclear antigen (PCNA), cyclin A, cyclin D1 and cyclin K) are downregulated during the period from 6 to $20 \mathrm{~h}$ [14]. Likewise, pro-apoptotic genes such as the caspases (CASP9, CASP3 and CASP2) and apoptotic protease activating factor (APAF) are induced during the same period [14]. However, a study reported that GSH depletion with BSO also activates Nrf2 signalling as an adaptive response in murine embryonic fibroblasts [64].

\section{Alcohol Metabolism in Liver}

The liver functions as the body's major homoeostatic regulator of several cellular components. Alcohol (ethanol) crosses gastrointestinal tract by simple diffusion into the blood stream [35]. Significant amount of ethanol is subjected to the first phase metabolism by gastric mucosal lining [56]. The diffused alcohol is taken to the liver by hepatic vein. Ethanol in liver sinusoids is diffused into the hepatocytes and gets oxidized to acetaldehyde by alcohol dehydrogenase (ADH). The conversion of ethanol to acetaldehyde by $\mathrm{ADH}$ utilizes $\mathrm{NAD}^{+}$and releases $\mathrm{NADH}$ [103]. Acetaldehyde is converted to acetate by acetaldehyde dehydrogenase, in mitochondria, which also requires $\mathrm{NAD}^{+}$and releases NADH. Acetate, an unstable compound, is readily converted into $\mathrm{H}_{2} \mathrm{O}$ or $\mathrm{CO}_{2}$.

The ADH-mediated metabolism of ethanol affects the hepatocytes in two ways: cellular redox imbalance through increased NADH production and acetaldehyde-protein adduct formation. The excess release of NADH affects fatty acid metabolism which results in the accumulation of triglyceride in hepatocyte [101]. It has been shown that alcohol-induced free fatty acid accumulation is prevented with the overexpression of Nrf2 [125].

In addition to redox changes, formation of acetaldehyde mediates ADH-induced ethanol metabolic toxicity [24]. Acetaldehyde forms adduct with cellular proteins, membrane lipids and DNA which potentiates liver injury and hepatocellular carcinoma [106]. The increased acetaldehyde also sensitizes the hepatocytes against TNF- $\alpha$ by affecting the GSH transport of mitochondria [68]. It has also been observed that acetaldehyde activates transcription factors-nuclear factor kappa-light-chain-enhancer of activated B cells (NF-kB) and activator protein 1 (AP-1) in liver cells (HepG2) [100].

Under chronic alcohol consumption the microsomal ethanol-oxidizing enzyme-CYP2E1 is activated [67]. The CYP2E1-induced ethanol oxidation to acetaldehyde releases superoxide anion which results in oxidative stress [67]. E47 cells exhibit increased oxidative stress by higher ROS level and lipid peroxidation which results in loss of cell viability [122, 22]. Consistently, CYP2E1-induced oxidative stress is modulated by the CYP2E1 inhibitors such as diallyl sulphide (DAS) and phenethyl isothiocyanate (PIC) in both in vivo and in vitro conditions [80, 16]. Thus, CYP2E1 plays a crucial role in the development of alcoholic liver damage mainly through oxidative stress.

\section{In Vitro Evidences for Ethanol-Inducible CYP2E1 and ADH Activity}

Several in vitro models have been established to study the adverse effects of ADH and CYP2E1 in liver cells. Human hepatoma cells (HepG2) are widely used as an in vitro model to study the effects of several xenobiotics in hepatocytes [37, 38]. Ethanol-induced cellular toxicity has been extensively studied in HepG2 cells transfected with human ADH- and/or CYP2E1-expressing genes.

The effects of acetaminophen toxicity and the role of CYP2E1 in the process have been studied in MVh2E1-9 (CYP2E1-transfected HepG2 cells) cells [26]. The ethanolinduced altered fatty acid metabolism has been studied utilizing the non-transfected HepG2 cells [3].

HepG2 cells, transfected with human CYP2E1expressing gene, (E47 cells) have been established to study CYP2E1-dependent ethanol hepatotoxicity [122, 22]. The proliferation rate of CYP2E1-overexpressing HepG2 cells is slower than the non-CYP2E1 expressing control HepG2 cells along with increased oxidative stress [22].

The ethanol-inducible CYP2E1-induced generation of ROS and oxidative stress has been well observed in HepG2 E9 cells [122]. HepG2 cells stably expressing CYP2E1 undergo apoptosis, which is not observed in HepG2 cells without CYP2E1 expression under ethanol treatment [122].

It has also been shown that ethanol in CYP2E1-overexpressing HepG2 cells (E47 cells) activates NF-Kappa B and AP-1 [100]. Endoplasmic reticulum dysfunction, which results in aggregation of unfolded proteins, is one of the possible mechanisms of CYP2E1-induced cytotoxicity [28]. Further, CYP2E1-induced cytotoxicity sensitizes the hepatocytes against TGF-beta 1 [128].

The CYP2E1 induced increases oxidative stress in the hepatocytes, activates fibrotic signals by enhancing proliferation of stellate cells and increases collagen type 1 protein [83]. The transcriptional activation of laminin in stellate cells is also enhanced by CYP2E1-induced oxidant stress in the hepatocytes [84]. CYP2E1 under GSH depletion activates ERK MAPK pathway in HepG2 cells [41].

Hence, in order to study the specific effect of combined $\mathrm{ADH}$ and CYP2E1 activity on chronic alcohol treatment in hepatocytes, VL-17A cells, which are HepG2 cells overexpressing both ADH and CYP2E1, have been established [31]. 


\section{The Role of Hyperglycaemia in Mediating Liver Injury}

Oxidative stress is associated with hyperglycaemia-mediated liver injury and as evident from the following studies, the depletion in GSH level forms an important component of the oxidative insult. Obesity and diabetes are associated with non-alcoholic steatohepatitis. Non-alcoholic steatohepatitis and alcoholic steatohepatitis share similar pathogenic mechanisms including increased expression of CYP2E1 [120]. Consistently, increased oxidative stress, and accumulation of malondialdehyde and 4-hydroxynonenal are observed in the hepatocytes of diabetic rats [114]. The generation of ketone bodies under obesity and type 2 diabetes could lead to CYP2E1 induction [99]. Further, high glucose sensitizes HepG2 cells towards apoptosis [18] and induces the expression of CYP2E1 in VL-17A cells [21]. Significant level of increased expression of ADH is also observed under high glucose treatment in VL-17A cells [20].

Reduction in GSH is observed in the liver in streptozotocin (STZ)-induced rats and the oral supplementation of esculetin to diabetic rats for 45 days significantly brings it back near normalcy [93]. The addition of sodium selenate to metformin is able to restore the hepatic GSH back to normal levels in a type 2 diabetes model which was achieved by feeding the rats with high-fat, high-fructose diet for 8 weeks followed by a low dose of STZ [102].

The diminished activities of antioxidant enzymes and reduced GSH in STZ-induced diabetic rats are improved upon the administration of a tetra hydroxy flavone fisetin [94]. Alpha-lipoic acid, a naturally occurring compound possessing antioxidant activity, administration practically normalises the activities of the indicators of hepatocellular injury, alanine and aspartate aminotransferases; lowers oxidative stress, as observed by the thiobarbituric acidreactive substance assay; restores the reduced GSH:GSSG ratio; and increases the protein sulphhydryl group content in a rat model of STZ-induced diabetes [30]. The total thiol and GSH levels in livers are markedly reduced in untreated STZ-induced diabetic rats; however, these parameters are increased in the diabetic rats following melatonin treatment [61]. The liver from STZ-induced diabetic rats exhibits a significant decrease in GSH and GSH-S-transferase, and treatment with resveratrol abrogates the decrease [46].

The gerbil Psammomys obesus, a unique model of nutritional diabetes resembling the disease in humans, displays many metabolic disturbances (hyperinsulinaemia, hyperglycaemia and dyslipidaemia) which is coupled with a decline in GSH and reduced GSH peroxidase activity; and treatment with silibinin alleviates most of the metabolic defects and largely restores antioxidant status [10]. The oral administration of interferon tau decreases ratios of the hepatic oxidized GSH to reduced GSH in Zucker diabetic fatty rats [111].

Oleanolic acid inhibits increased cellular and mitochondrial ROS production in obese diabetic $\mathrm{db} / \mathrm{db}$ mice and the authors speculate that Nrf2-GCLc-mediated stabilization of mitochondrial GSH pool may be involved in the protective actions of oleanolic acid [118]. However, the hepatic levels of cysteine and its metabolites, such as hypotaurine, taurine, and $\mathrm{GSH}$, are increased despite inhibition of the transsulphuration of homocysteine to cysteine in non-obese type- 2 diabetic Goto-Kakizaki rats [57]. The elevated hepatic taurine and GSH levels may be attributed to the upregulation of cysteine dioxygenase expression and the increased cysteine availability for GSH synthesis [57].

Methylglyoxal (MGO) is a dicarbonyl that reacts with amino acids and nucleic acids to form advanced glycation end products, which may contribute to diabetes and its cardiovascular complications [76]. MGO detoxification through the glyoxalase (GLO) pathway is GSH-dependent [76]. Hepatic GSH is $68-71 \%$ lower at $6-12 \mathrm{~h}$ following BSO administration to rats, and MGO is $27 \%$ higher at $12 \mathrm{~h} \mathrm{[76].} \mathrm{At} 12 \mathrm{~h}$, hepatic D-lactate is $13 \%$ lower and GLO activity is $52 \%$ lower following BSO, which is fully restored by the exogenous addition of GSH [76]. The hepatic GSH is inversely related to hepatic MGO and positively correlates with the hepatic GLO activity whereas the hepatic GLO activity is positively correlated with the hepatic D-lactate [76]. Thus, GSH depletion in vivo increases the hepatic MGO accumulation by impairing its GSH-dependent, GLO-mediated detoxification to D-lactate independent of oxidative stress [76]. Further, MG is believed to cause insulin resistance by inducing inflammation and pancreas damage [63]. In MG-induced diabetic rats, ankaflavin elevates the GSH levels in liver and pancreas of MG-induced rats [63].

\section{ADH/CYP2E1 and GSH}

In the hepatocytes, chronic alcohol exposure causes an increase in reduced (GSH) and a decrease in oxidized GSH (GSSG) [48]. In contrast, $40 \%$ of loss in GSH is observed in liver of rats fed alcohol and high-fat diet, despite increased expression of transcription factors-NF-kB, ARE and AP-1 which regulate GSH synthesis [70]. The loss of induction of the $\gamma$-glutamyl cysteine synthase-light subunit (GCS-LS) is considered to be the responsible factor for loss of liver GSH level even under ethanol treatment [70]. It has also been shown that acetaldehyde plays a major role in the depletion of GSH in the isolated hepatocytes [117]. The mitochondrial depletion of GSH is 
prevented under overexpression of Nrf2 in a mouse model of alcoholic liver injury [125].

The CYP2E1-induced oxidative stress increases the intracellular GSH level by increasing the activation of GCS through Nrf2 nuclear translocation [74, 75, 84, 17]. The exogenous induction of GSH depletion causes mitochondrial-dependent apoptosis in CYP2E1-expressing HepG2 cells (E47 cells) [123]. Similarly, GSH is increased in VL17A cells exposed to high glucose [21] or chronic ethanol [19] and it is increased to an intermediate extent in VL-17A cells subjected to chronic ethanol plus high glucose [20].

\section{Status of GSH in In Vivo Models}

The liver content of GSH is lower in mice fed methioninecholine-deficient diet for 4 and 6 weeks exhibiting induced nonalcoholic fatty liver disease [54]. 3-Hydroxy-3methylglutaryl-CoA lyase deficiency is a disorder biochemically characterized by the predominant accumulation of 3-hydroxy-3-methylglutarate (HMG), 3-methylglutarate (MGA), 3-methylglutaconate and 3-hydroxyisovalerate in tissues and in vivo administration of HMG and MGA significantly decrease GSH concentration in liver in young rats [25].

The hepatic S-adenosylmethionine, cysteine and GSH levels, reduced in the rats receiving a liquid ethanol diet for 6 weeks, are increased by betaine supplementation [57]. Further, cysteine dioxygenase is downregulated, which appears to account for the increment in the cysteine availability for GSH synthesis in the rats supplemented with betaine [57]. In another study involving ageing rats, doubling the dietary intake of cysteine (free cysteine) through long-term dietary fortification in old rats increases the cysteine and GSH pools in liver thus alleviating ageassociated low-grade inflammation and resulting in global physiological benefits [116].

A study demonstrated that the hypocholesterolaemic effect of rice protein is attributable to inducing antioxidative response and depressing oxidative damage in adult rats fed cholesterol-free/enriched diets [13]. After 2 weeks of feeding rice protein in adult rats fed with and without cholesterol, significantly increased hepatic and plasma GSH contents are observed whereas the hepatic accumulation of GSSG is significantly reduced.

Although GSH content does not change significantly in the intact rat liver after intraperitoneal NAC administration, the cysteine content increases rapidly [126]. However, in liver depleted of GSH with DEM, NAC administration restores GSH contents [126]. A similar phenomenon is observed in the perfused rat liver where liver perfusion of DEM-injected rats with NAC restores GSH content [126]. The findings of the study indicate that NAC stimulates
GSH synthesis in the GSH-depleted intact liver and in the perfused rat liver [126].

GSH depletion-a primary cause of acetaminophenmediated injury is significantly attenuated in interleukin-4 knockout (IL-4 ${ }^{-1-}$ ) mice and the authors conclude that IL$4^{-1-}$ mice are protected from acetaminophen-induced liver injury due to the reduced depletion of GSH, which prevents liver damage and tissue inflammation [91]. One of the most abundant dietary polyphenols_-chlorogenic acid reverses acetaminophen-decreased liver GSH levels in mice in vivo [52]. Very long chain (C22-C24) ceramides are synthesized by ceramide synthase 2 (CerS2) and a CerS2 null mouse displays hepatopathy because of depletion of $\mathrm{C} 22-$ $\mathrm{C} 24$ ceramides, elevation of $\mathrm{C} 16$-ceramide and/or elevation of sphinganine [89]. Unexpectedly, CerS2 null mice are resistant to the acetaminophen-induced hepatotoxicity accompanied by increased level of GSH [89].

The fatty acid synthase inhibitor cerulenin increases hepatic GSH content in some of the steatotic ob/ob mice administered cerulenin [23]. The d-Galactosamine (GalN) and lipopolysaccharide (LPS) treatment that results in hepatic inflammation and subsequent fulminant hepatic failure in mice decreases the liver GSH content which is attenuated by hemin [haem oxygenase-1 (HO-1) inducer], but zinc protoporphyrin [(HO-1) inhibitor] reverses the effects of hemin [59].

\section{GSH and Drug Detoxification: the Role of GSH S-Transferases}

Glutathione S-transferases (GSTs) are involved in drug detoxification through the conjugation of reactive drug metabolites to GSH [34, 58, 85]. The GSTs catalyze the nucleophilic attack of GSH on the electrophilic centre of a number of xenobiotic compounds, including several chemotherapeutic drugs [58, 85]. Apart from conjugation of xenobiotics to GSH, many other activities are also associated with the GSTs, including steroid and leukotriene biosynthesis, peroxide degradation, double-bond cis-trans isomerization, dehydroascorbate reduction, Michael addition, and noncatalytic 'ligandin' activity (ligand binding and transport) [85].

The GSTs are present in different subcellular compartments including cytosol, mitochondria, endoplasmic reticulum, nucleus and plasma membrane [97]. The regulation and function of the GSTs have implications in cell growth, oxidative stress as well as disease progression and prevention [97]. The genetically determined deficiencies in GSTs might be a risk factor for the idiosyncratic adverse drug reactions resulting from the formation of reactive drug metabolites [34]. Altered GST expression has been implicated in hepatic, cardiac and neurological diseases [97]. 
Mitochondria-specific GSTK has also been implicated in obesity, diabetes and related metabolic disorders [97]. In context of this review, it is interesting to note that studies have shown that silencing the GSTA4 (GST alpha) gene results in mitochondrial dysfunction, as is also seen in GSTA4 null mice, which could contribute to insulin resistance in type 2 diabetes [97].

The ability of four recombinant human GSTs (hGST A1-1, hGST M1-1, hGSTP1-1 and hGST T1-1) to catalyze the GSH conjugation of reactive metabolites of clozapine, formed in vitro by human and rat liver microsomes and drug-metabolizing P450 BM3 mutant-P450 102A1M11H, has been studied [33]. In the presence of three of the GSTs, hGSTP1-1, hGST M1-1 and hGST A1-1, the total GSH conjugation is strongly increased in all bioactivation systems tested [33]. The highest activity is observed with hGSTP1-1, whereas hGST M1-1 and hGST A1-1 show slightly lower activity [33]. Interestingly, the addition of hGSTs results in major changes in the regioselectivity of GSH conjugation of the reactive clozapine metabolite, possibly due to the different active site geometries of hGSTs [33]. The authors conclude that the human GSTs may play a significant role in the inactivation of reactive intermediates of clozapine [33].

hGSTP1-1 is polymorphic in the human population with a number of single nucleotide polymorphisms that yield an amino acid change in the encoded protein [34]. Three allelic variants of hGSTP1-1 containing an Ile105Val or Ala114Val substitution, or a combination of both, have been most widely studied and show different activities when compared to wild-type hGSTP1-1*A (Ile105/ Ala114) [34]. The ability of these allelic variants to catalyze the GSH conjugation of reactive metabolites of acetaminophen, clozapine and diclofenac formed by bioactivation in in vitro incubations by human liver microsomes and drug-metabolizing P450 BM3 mutants has been studied [34]. The different hGSTP1-1 mutants show slightly altered regioselectivities in the formation of the individual GSH conjugates of clozapine which suggests that the binding orientation of the reactive nitrenium ion of clozapine is affected by the mutations [34]. For diclofenac, a significant decrease in activity in GSH conjugation of diclofenac $1^{\prime}, 4^{\prime}$-quinone imine is observed for variants hGSTP1-1*B (Val105/Ala114) and hGSTP1-1*C (Val105/ Val114) (Dragovic et al.). However, since the differences in total GSH conjugation activity catalyzed by these allelic variants are not higher than $30 \%$, the differences in inactivation of reactive intermediates by hGSTP1-1 are not likely to be a major factor in determining interindividual difference in susceptibility to adverse drug reactions induced by the drugs studied [34].

In the presence of GSH, the chemotherapeutic drug chlorambucil (CBL) behaves as an efficient substrate for human GSTA1-1 (hGSTA1-1). In the absence of GSH, $\mathrm{CBL}$ acts as an alkylating irreversible inhibitor for hGSTA1-1 [58]. The GSTs are known to be overexpressed in tumor, and naturally occurring isothiocyanates, such as benzyl isothiocyanate (BITC), are effective cancer chemopreventive compounds [95]. The presence of the sulphur atom from the isothiocyanate moiety in BITC-SG conjugate is found to be crucial for its irreversible inhibition of GST P1-1 [95].

Icariside II activates the nuclear translocation of $\mathrm{Nrf} 2$ and upregulates the expression of Nrf2-related antioxidant protein HO-1 and GST in HepG2 cells [45]. Further, icariside II significantly increases the phosphorylation levels of ERK1/2, Akt and JNK1/2 suggesting that the Nrf2/ARE pathway plays an important role in the regulation of icariside-mediated antioxidant effects in HepG2 cells [45].

The null mutation of GSTM1 and GSTT1 is reported to correlate statistically with an abnormal increase in the plasma levels of alanine aminotransferase or aspartate aminotransferase caused by troglitazone in diabetic patients [119]. The involvement of the human GST isoforms in the GSH conjugation of reactive metabolites of troglitazone using recombinant GST enzymes has been investigated [88]. Five reported GSH conjugates of reactive metabolites are produced from troglitazone after incubation with liver microsomes, NADPH, and GSH in a GSH concentration-dependent manner [88]. The addition of human recombinant GSTA1, GSTA2, GSTM1 or GSTP1 protein to the incubation mixture further increases the GSH conjugates [88]. Thus, the GST isoforms contribute differently to the GSH conjugation of individual reactive metabolites of troglitazone, and GSTM1 is the most important GST isoform in the GSH conjugation of a specific reactive metabolite produced from the cytotoxic, quinone-form metabolite of troglitazone [88].

The role for GSTs in the detoxification of the reactive metabolite-2-ABT-S-oxide (M1) of zileuton, an agent which targets the leukotriene pathway through inhibition of 5-lipoxygenase (5-LO), has been investigated [55]. The non-enzymatic conjugation with M1 and GSH is accelerated in the presence of GSTA1-1, GSTM1-1 and GSTP1-1 [55]. M1 inhibits GSTM1-1 and GSTP1-1 to a greater extent as compared with GSTA1-1 [55]. In the case of GSTA1-1, the inhibition is observed to be reversible, whereas M1 inhibition of GSTM1-1 and GSTP1-1 is found to be irreversible under identical conditions [55]. Thus, the authors demonstrate the presence of GSTM1-1 in liver and conclude that the alkylation and potential irreversible inactivation of this isoform in vivo could contribute to an understanding of the hepatotoxicity associated with zileuton [55]. 


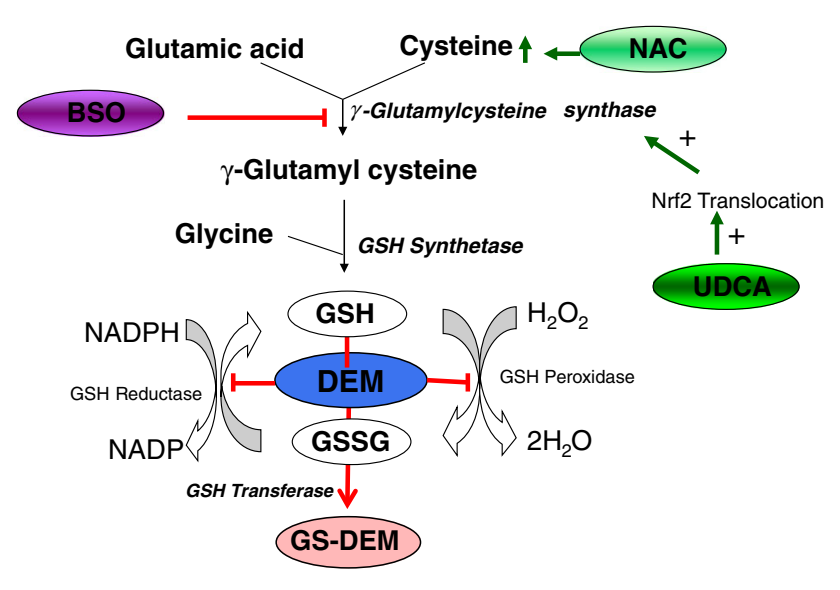

Fig. 3 Exogenous modulation of glutathione synthesis

\section{Modulation of Cellular GSH Through Exogenous Agents}

The exogenous GSH modulators, such as NAC, BSO, ursodeoxycholic acid (UDCA) and diethyl maleate (DEM), are widely used to alter intracellular GSH in cells [27] and their mechanisms of actions are shown in Fig. 3.

\section{NAC and UDCA}

NAC treatment is found to abrogate acroline-induced hepatotoxicity associated with reduced GSH level, disturbed mitochondrial integrity, endoplasmic reticulum and JNK activation [78]. The long-term exposure of alcohol is found to sensitize the hepatocytes against TNF-induced toxicity by inhibition of $\mathrm{Nf}-\mathrm{\kappa B}$ associated with increased lipid peroxidation and accumulation of 4-HNE [32]. The treatment of the alcohol-treated hepatocytes with NAC has a protective action against ethanol-induced Nf- $\mathrm{\kappa B}$ inhibition by reducing lipid peroxidation-induced 4-HNE accumulation [32].

NAC provides the cysteine precursor for GSH synthesis and increases intracellular GSH level [51]. The ethanolinduced cytotoxicity in CYP2E1-overexpressing HepG2 cells (HepG2 E9 cells) is abrogated by NAC treatment [122]. Further the cytotoxicity of acetaminophen is abrogated by NAC in HepG2 cells [26].

UDCA, a hydrophilic bile salt, enhances the expression and nuclear translocation of Nrf2 thereby increasing expression of GSH synthesizing enzymes and the GSH level through PI3K/Akt pathway [87, 4]. Thus, UDCA prevents $\mathrm{H}_{2} \mathrm{O}_{2}$ - or ethanol-induced toxicity in rat hepatocytes by increasing the intracellular GSH level [77, 79]. UDCA also enhances the hepatic membrane stability against oxidative insult [72].

\section{BSO and DEM}

BSO, an inhibitor of the GCS, has been used extensively to study the role of GSH in CYP2E1-induced toxicity in HepG2 cells [44, 75, 73]. The S-alkyl moiety of the sulphoximine binds at the active site of the gamma-glutamyl cysteine synthetase that normally binds the acceptor amino acid [43, 44].

Besides, BSO involved in the depletion of GSH increases oxidative stress in the cells through increased sensitivity of the cells to $\mathrm{H}_{2} \mathrm{O}_{2}$ and several other oxidative stress-inducing agents [27]. GSH depletion with BSO is effective in HepG2 cells overexpressing CYP2E1 than HepG2 cells devoid of ADH and CYP2E1 expression [22]. BSO-induced GSH depletion in CYP2E1-overexpressing HepG2 cells (E47 cells) activates NF-Kappa B and AP-1 [100]. BSO-induced depletion of GSH in CYP2E1expressing HepG2 cells causes differential induction of apoptosis and necrosis associated with decreased mitochondrial membrane stability and increased caspase 3 activity [123]. The cytotoxicity of acetaminophen is enhanced by BSO in HepG2 cells [107].

Another mode of GSH depletion occurs through GSH transferase-mediated reactions where DEM, an electrophilic reagent and a mildly reactive alpha, $\beta$ unsaturated carbonyl compound conjugates with GSH which is catalyzed by GSH transferase which leads to the formation of hydrophilic GSH conjugates and causes rapid depletion of GSH [11, 92, 27] [90]. DEM has been shown to cause cytoskeleton disruptions in Clara cells which include cell swelling and membrane bleb formation [90], and disruption in actin and tubulin filaments in hepatocytes [36, 82]. DEM-induced GSH depletion causes lipid peroxidationinduced cell death in hepatocyte [113].

\section{Future Directions and Perspectives}

It would be interesting to investigate whether GSH supplementation or its depletion ameliorates or aggravates hyperglycaemia- or chronic alcohol-mediated oxidative stress and injury in liver, respectively, and to what degree do the GSH-modulating agents affect the damage due to the parent toxins, i.e. high cellular concentrations of alcohol or glucose.

\section{Conclusions}

As evident from the literature, GSH plays a crucial role in maintaining the antioxidant balance and lowering the oxidative stress in the cell. The rate-limiting step in GSH biosynthesis is catalyzed by GCS, and GSH biosynthesis is 
regulated by Nrf2 which itself is regulated by several factors. GSH besides attenuating oxidative stress also has several other beneficial effects in the cell which include decreases in apoptosis and methylglyoxal-induced toxicity. The metabolism of alcohol by ADH and CYP2E1 leads to increased acetaldehyde and ROS formation. Several in vitro studies have shown the roles of ADH and CYP2E1 in ethanol metabolism. Further, hyperglycaemia is emerging as an important player in aggravating liver injury. Both hyperglycaemia and chronic alcoholism induce ADH and CYP2E1. Several in vivo studies utilizing animal models have shown the essential role of GSH in lowering cellular oxidative stress. The depletion in the hepatic GSH level is an important mechanism for hyperglycaemia-mediated oxidative injury. Further, impairment of the activity of GSH transferase or polymorphisms in the different isoforms of GSH transferase lead to decreased drug detoxification. The depletion of GSH potentiates CYP2E1mediated oxidative stress and injury in liver cells. The GSH donors-NAC and UDCA increase the beneficial effects of GSH in different cell culture and animal models and the opposite effects were observed with the agents causing GSH depletion-BSO and DEM. Hence, GSH regulation in the cell occurs through diverse mechanisms with Nrf2 playing a key role in the process.

\section{Acknowledgments Aparajita Dey (Principal Investigator) acknowledges the financial support received from Department of Biotechnology, New Delhi, India (RAPID GRANT FOR YOUNG INVESTIGATORS). S Mathan Kumar is grateful to Department of Biotechnology, New Delhi, India (RAPID GRANT FOR YOUNG INVESTIGATORS) for awarding the Junior and Senior Research Fellowships.}

Conflict of interest The authors declare that there are no conflicts of interest.

\section{References}

1. Alisi A, Piemonte F, Pastore A, Panera N, Passarelli C, Tozzi G, Petrini S, Pietrobattista A, Bottazzo GF, Nobili V (2009) Glutathionylation of p65NF-kappaB correlates with proliferating/ apoptotic hepatoma cells exposed to pro- and anti-oxidants. Int $\mathbf{J}$ Mol Med 24(3):319-326

2. Amaral JD, Castro RE, Sola S, Steer CJ, Rodrigues CM (2007) p53 is a key molecular target of ursodeoxycholic acid in regulating apoptosis. J Biol Chem 282(47):34250-34259. doi:10. 1074/jbc.M704075200

3. Angeletti C, de Alaniz MJ (1996) Effect of ethanol on glycerolipid and fatty acid metabolism in Hep G2 human-hepatoma cells. Acta Physiol Pharmacol Ther Latinoam 46(2):57-69

4. Arisawa S, Ishida K, Kameyama N, Ueyama J, Hattori A, Tatsumi Y, Hayashi H, Yano M, Hayashi K, Katano Y, Goto H, Takagi K, Wakusawa S (2009) Ursodeoxycholic acid induces glutathione synthesis through activation of PI3K/Akt pathway in HepG2 cells. Biochem Pharmacol 77(5):858-866. doi:10.1016/j. bcp.2008.11.012
5. Bai J, Cederbaum AI (2006) Overexpression of CYP2E1 in mitochondria sensitizes HepG2 cells to the toxicity caused by depletion of glutathione. J Biol Chem 281(8):5128-5136. doi:10.1074/jbc.M510484200

6. Balmer ML, Siegrist K, Zimmermann A, Dufour JF (2009) Effects of ursodeoxycholic acid in combination with vitamin $\mathrm{E}$ on adipokines and apoptosis in patients with nonalcoholic steatohepatitis. Liver Int 29(8):1184-1188. doi:10.1111/j.14783231.2009.02037.x

7. Bannai S, Tateishi N (1986) Role of membrane transport in metabolism and function of glutathione in mammals. J Membr Biol 89(1):1-8

8. Barone M, Francavilla A, Polimeno L, Ierardi E, Romanelli D, Berloco P, Di Leo A, Panella C (1996) Modulation of rat hepatocyte proliferation by bile salts: in vitro and in vivo studies. Hepatology 23(5):1159-1166. doi:10.1053/jhep.1996. v23.pm0008621149

9. Blouet C, Mariotti F, Azzout-Marniche D, Mathe V, Mikogami T, Tome D, Huneau JF (2007) Dietary cysteine alleviates sucrose-induced oxidative stress and insulin resistance. Free Radic Biol Med 42(7):1089-1097. doi:10.1016/j.freeradbiomed. 2007.01.006

10. Bouderba S, Sanz MN, Sanchez-Martin C, El-Mir MY, Villanueva GR, Detaille D, Koceir EA (2012) Hepatic mitochondrial alterations and increased oxidative stress in nutritional diabetes-prone Psammomys obesus model. Exp Diabetes Res 2012:430176. doi:10.1155/2012/430176

11. Boyland E, Chasseaud LF (1967) Enzyme-catalysed conjugations of glutathione with unsaturated compounds. Biochem J 104(1):95-102

12. Brandsch C, Schmidt T, Behn D, Weisse K, Mueller AS, Stangl GI (2010) Glutathione deficiency down-regulates hepatic lipogenesis in rats. Lipids Health Dis 9:50. doi:10.1186/1476-511X9-50

13. Cai J, Yang L, He HJ, Xu T, Liu HB, Wu Q, Ma Y, Liu QH, Nie MH (2014) Antioxidant capacity responsible for a hypocholesterolemia is independent of dietary cholesterol in adult rats fed rice protein. Gene 533(1):57-66. doi:10.1016/j.gene.2013.09. 124

14. Casey W, Anderson S, Fox T, Dold K, Colton H, Morgan K (2002) Transcriptional and physiological responses of HepG2 cells exposed to diethyl maleate: time course analysis. Physiol Genomics 8(2):115-122. doi:10.1152/physiolgenomics.00064. 2001

15. Castro RE, Ferreira DM, Afonso MB, Borralho PM, Machado MV, Cortez-Pinto H, Rodrigues CM (2013) miR-34a/SIRT1/p53 is suppressed by ursodeoxycholic acid in the rat liver and activated by disease severity in human non-alcoholic fatty liver disease. J Hepatol 58(1):119-125. doi:10.1016/j.jhep.2012.08. 008

16. Cederbaum AI (1998) Ethanol-related cytotoxicity catalyzed by CYP2E1-dependent generation of reactive oxygen intermediates in transduced HepG2 cells. BioFactors 8(1-2):93-96

17. Cederbaum AI (2006) Cytochrome P450 2E1-dependent oxidant stress and upregulation of anti-oxidant defense in liver cells. J Gastroenterol Hepatol 21(Suppl 3):S22-S25. doi:10.1111/j. 1440-1746.2006.04595.x

18. Chandrasekaran K, Swaminathan K, Chatterjee S, Dey A (2010) Apoptosis in HepG2 cells exposed to high glucose. Toxicol In Vitro 24(2):387-396. doi:10.1016/j.tiv.2009.10.020

19. Chandrasekaran K, Swaminathan K, Kumar SM, Chatterjee S, Clemens DL, Dey A (2011) Elevated glutathione level does not protect against chronic alcohol mediated apoptosis in recombinant human hepatoma cell line VL-17A over-expressing alcohol metabolizing enzymes-alcohol dehydrogenase and Cytochrome 
P450 2E1. Toxicol In Vitro 25(4):969-978. doi:10.1016/j.tiv. 2011.03.006

20. Chandrasekaran K, Swaminathan K, Kumar SM, Clemens DL, Dey A (2012) Increased oxidative stress and toxicity in ADH and CYP2E1 overexpressing human hepatoma VL-17A cells exposed to high glucose. Integr Biol (Camb) 4(5):550-563. doi:10.1039/c2ib00155a

21. Chandrasekaran K, Swaminathan K, Mathan Kumar S, Clemens DL, Dey A (2012) In vitro evidence for chronic alcohol and high glucose mediated increased oxidative stress and hepatotoxicity. Alcohol Clin Exp Res 36(6):1004-1012. doi:10.1111/j.15300277.2011.01697.x

22. Chen Q, Cederbaum AI (1998) Cytotoxicity and apoptosis produced by cytochrome P450 2E1 in Hep G2 cells. Mol Pharmacol 53(4):638-648

23. Cheng G, Palanisamy AP, Evans ZP, Sutter AG, Jin L, Singh I, May H, Schmidt MG, Chavin KD (2013) Cerulenin blockade of fatty acid synthase reverses hepatic steatosis in ob/ob mice. PLoS One 8(9):e75980. doi:10.1371/journal.pone.0075980

24. Clemens DL, Forman A, Jerrells TR, Sorrell MF, Tuma DJ (2002) Relationship between acetaldehyde levels and cell survival in ethanol-metabolizing hepatoma cells. Hepatology 35(5):1196-1204. doi:10.1053/jhep.2002.32668

25. da Rosa MS, Seminotti B, Amaral AU, Fernandes CG, Gasparotto J, Moreira JC, Gelain DP, Wajner M, Leipnitz G (2013) Redox homeostasis is compromised in vivo by the metabolites accumulating in 3-hydroxy-3-methylglutaryl-CoA lyase deficiency in rat cerebral cortex and liver. Free Radic Res 47(12): 1066-1075. doi:10.3109/10715762.2013.853876

26. Dai Y, Cederbaum AI (1995) Cytotoxicity of acetaminophen in human cytochrome P4502E1-transfected HepG2 cells. J Pharmacol Exp Ther 273(3):1497-1505

27. Deneke SM, Fanburg BL (1989) Regulation of cellular glutathione. Am J Physiol 257(4 Pt 1):L163-L173

28. Dey A, Kessova IG, Cederbaum AI (2006) Decreased protein and mRNA expression of ER stress proteins GRP78 and GRP94 in HepG2 cells over-expressing CYP2E1. Arch Biochem Biophys 447(2):155-166. doi:10.1016/j.abb.2006.01.013

29. Ding Y, Choi KJ, Kim JH, Han X, Piao Y, Jeong JH, Choe W, Kang I, Ha J, Forman HJ, Lee J, Yoon KS, Kim SS (2008) Endogenous hydrogen peroxide regulates glutathione redox via nuclear factor erythroid 2-related factor 2 downstream of phosphatidylinositol 3-kinase during muscle differentiation. Am J Pathol 172(6):1529-1541. doi:10.2353/ajpath.2008.070429

30. Dinic S, Arambasic J, Mihailovic M, Uskokovic A, Grdovic N, Markovic J, Karadzic B, Poznanovic G, Vidakovic M (2013) Decreased O-GlcNAcylation of the key proteins in kinase and redox signalling pathways is a novel mechanism of the beneficial effect of alpha-lipoic acid in diabetic liver. Br J Nutr 110(3):401-412. doi:10.1017/S0007114512005429

31. Donohue TM, Osna NA, Clemens DL (2006) Recombinant Hep G2 cells that express alcohol dehydrogenase and cytochrome P450 2E1 as a model of ethanol-elicited cytotoxicity. Int $\mathrm{J}$ Biochem Cell Biol 38(1):92-101. doi:10.1016/j.biocel.2005.07. 010

32. Dou X, Li S, Wang Z, Gu D, Shen C, Yao T, Song Z (2012) Inhibition of NF-kappaB activation by 4-hydroxynonenal contributes to liver injury in a mouse model of alcoholic liver disease. Am J Pathol 181(5):1702-1710. doi:10.1016/j.ajpath.2012. 08.004

33. Dragovic S, Boerma JS, van Bergen L, Vermeulen NP, Commandeur JN (2010) Role of human glutathione S-transferases in the inactivation of reactive metabolites of clozapine. Chem Res Toxicol 23(9):1467-1476. doi:10.1021/tx100131f

34. Dragovic S, Boerma JS, Vermeulen NP, Commandeur JN (2013) Effect of human glutathione S-transferases on glutathione-dependent inactivation of cytochrome P450-dependent reactive intermediates of diclofenac. Chem Res Toxicol. doi:10.1021/tx400204d

35. Dubowski KM (1985) Absorption, distribution and elimination of alcohol: highway safety aspects. J Stud Alcohol Suppl 10:98-108

36. Dumont M, D'Hont C, Durand-Schneider AM, Legrand-Defretin VL, Feldmann G, Erlinger S (1991) Inhibition by colchicine of biliary secretion of diethylmaleate in the rat: evidence for microtubule-dependent vesicular transport. Hepatology 14(1):10-15

37. Duthie SJ, Grant MH (1989) The toxicity of menadione and mitozantrone in human liver-derived Hep G2 hepatoma cells. Biochem Pharmacol 38(8):1247-1255

38. Duthie SJ, Melvin WT, Burke MD (1994) Bromobenzene detoxification in the human liver-derived HepG2 cell line. Xenobiotica 24(3):265-279. doi:10.3109/00498259409043238

39. Furfaro AL, Nitti M, Marengo B, Domenicotti C, Cottalasso D, Marinari UM, Pronzato MA, Traverso N (2012) Impaired synthesis contributes to diabetes-induced decrease in liver glutathione. Int J Mol Med 29(5):899-905. doi:10.3892/ijmm.2012.915

40. Gomez-Quiroz LE, Factor VM, Kaposi-Novak P, Coulouarn C, Conner EA, Thorgeirsson SS (2008) Hepatocyte-specific c-Met deletion disrupts redox homeostasis and sensitizes to Fas-mediated apoptosis. J Biol Chem 283(21):14581-14589. doi:10. 1074/jbc.M707733200

41. Gong P, Cederbaum AI, Nieto N (2003) Increased expression of cytochrome P450 2E1 induces heme oxygenase-1 through ERK MAPK pathway. J Biol Chem 278(32):29693-29700. doi:10. 1074/jbc.M304728200

42. Gonzalez R, Ferrin G, Hidalgo AB, Ranchal I, Lopez-Cillero P, Santos-Gonzalez M, Lopez-Lluch G, Briceno J, Gomez MA, Poyato A, Villalba JM, Navas P, de la Mata M, Muntane J (2009) $N$-acetylcysteine, coenzyme Q10 and superoxide dismutase mimetic prevent mitochondrial cell dysfunction and cell death induced by d-galactosamine in primary culture of human hepatocytes. Chem Biol Interact 181(1):95-106. doi:10.1016/j. cbi.2009.06.003

43. Griffith OW, Anderson ME, Meister A (1979) Inhibition of glutathione biosynthesis by prothionine sulfoximine (S-n-propyl homocysteine sulfoximine), a selective inhibitor of gammaglutamylcysteine synthetase. J Biol Chem 254(4):1205-1210

44. Griffith OW, Meister A (1979) Potent and specific inhibition of glutathione synthesis by buthionine sulfoximine (S-n-butyl homocysteine sulfoximine). J Biol Chem 254(16):7558-7560

45. Gu J, Sun X, Wang G, Li M, Chi M (2011) Icariside II enhances Nrf2 nuclear translocation to upregulate phase II detoxifying enzyme expression coupled with the ERK, Akt and JNK signaling pathways. Molecules 16(11):9234-9244. doi:10.3390/ molecules 16119234

46. Hamadi N, Mansour A, Hassan MH, Khalifi-Touhami F, Badary O (2012) Ameliorative effects of resveratrol on liver injury in streptozotocin-induced diabetic rats. J Biochem Mol Toxicol 26(10):384-392. doi:10.1002/jbt.21432

47. Harvey CJ, Thimmulappa RK, Singh A, Blake DJ, Ling G, Wakabayashi N, Fujii J, Myers A, Biswal S (2009) Nrf2-regulated glutathione recycling independent of biosynthesis is critical for cell survival during oxidative stress. Free Radic Biol Med 46(4):443-453. doi:10.1016/j.freeradbiomed.2008.10.040

48. Hassing JM, Hupka AL, Stohs SJ, Yoon PC (1979) Hepatic glutathione levels in D-penicillamine-fed ethanol-dependent rats. Res Commun Chem Pathol Pharmacol 25(2):389-394

49. Hopkins FG (1921) On an Autoxidisable Constituent of the Cell. Biochem J 15(2):286-305

50. Hopkins FG (1929) Glutathione: a reinvestigation. J Biol Chem 84:269-320

51. Issels RD, Nagele A, Eckert KG, Wilmanns W (1988) Promotion of cystine uptake and its utilization for glutathione 
biosynthesis induced by cysteamine and $N$-acetylcysteine. Biochem Pharmacol 37(5):881-888

52. Ji L, Jiang P, Lu B, Sheng Y, Wang X, Wang Z (2013) Chlorogenic acid, a dietary polyphenol, protects acetaminopheninduced liver injury and its mechanism. J Nutr Biochem 24(11):1911-1919. doi:10.1016/j.jnutbio.2013.05.007

53. Jimenez-Lopez JM, Wu D, Cederbaum AI (2008) Synergistic toxicity induced by prolonged glutathione depletion and inhibition of nuclear factor-kappaB signaling in liver cells. Toxicol In Vitro 22(1):106-115. doi:10.1016/j.tiv.2007.08.012

54. Jorgacevic B, Mladenovic D, Ninkovic M, Prokic V, Stankovic M, Aleksic V, Cerovic I, Vukicevic RJ, Vucevic D, Radosavljevic T (2013) Dynamics of oxidative/nitrosative stress in mice with methionine-choline-deficient diet-induced nonalcoholic fatty liver disease. Hum Exp Toxicol. doi:10.1177/ 0960327113506723

55. Joshi EM, Heasley BH, Macdonald TL (2009) 2-ABT-S-oxide detoxification by glutathione S-transferases A1-1, M1-1 and P11: implications for toxicity associated with zileuton. Xenobiotica 39(3):197-204. doi:10.1080/00498250802651976

56. Julkunen RJ, Tannenbaum L, Baraona E, Lieber CS (1985) First pass metabolism of ethanol: an important determinant of blood levels after alcohol consumption. Alcohol 2(3):437-441

57. Jung YS, Kim SJ, Kwon DY, Ahn CW, Kim YS, Choi DW, Kim YC (2013) Alleviation of alcoholic liver injury by betaine involves an enhancement of antioxidant defense via regulation of sulfur amino acid metabolism. Food Chem Toxicol 62C:292-298. doi:10.1016/j.fct.2013.08.049

58. Karpusas M, Axarli I, Chiniadis L, Papakyriakou A, Bethanis K, Scopelitou K, Clonis YD, Labrou NE (2013) The interaction of the chemotherapeutic drug chlorambucil with human glutathione transferase A1-1: kinetic and structural analysis. PLoS One 8(2):e56337. doi:10.1371/journal.pone.0056337

59. Kim SJ, Lee SM (2013) NLRP3 inflammasome activation in d-galactosamine and lipopolysaccharide-induced acute liver failure: role of heme oxygenase-1. Free Radic Biol Med 65C:997-1004. doi:10.1016/j.freeradbiomed.2013.08.178

60. Kong AN, Owuor E, Yu R, Hebbar V, Chen C, Hu R, Mandlekar $S$ (2001) Induction of xenobiotic enzymes by the MAP kinase pathway and the antioxidant or electrophile response element (ARE/EpRE). Drug Metab Rev 33(3-4):255-271. doi:10.1081/ DMR-120000652

61. Korkmaz GG, Uzun H, Cakatay U, Aydin S (2012) Melatonin ameliorates oxidative damage in hyperglycemia-induced liver injury. Clin Invest Med 35(6):E370-E377

62. Langston W, Circu ML, Aw TY (2008) Insulin stimulation of gamma-glutamylcysteine ligase catalytic subunit expression increases endothelial GSH during oxidative stress: influence of low glucose. Free Radic Biol Med 45(11):1591-1599. doi:10. 1016/j.freeradbiomed.2008.09.013

63. Lee BH, Hsu WH, Chang YY, Kuo HF, Hsu YW, Pan TM (2012) Ankaflavin: a natural novel PPARgamma agonist upregulates $\mathrm{Nrf} 2$ to attenuate methylglyoxal-induced diabetes in vivo. Free Radic Biol Med 53(11):2008-2016. doi:10.1016/j. freeradbiomed.2012.09.025

64. Lee HR, Cho JM, Shin DH, Yong CS, Choi HG, Wakabayashi N, Kwak MK (2008) Adaptive response to GSH depletion and resistance to L-buthionine-(S, R)-sulfoximine: involvement of Nrf2 activation. Mol Cell Biochem 318(1-2):23-31. doi:10. 1007/s11010-008-9853-y

65. Lee JM, Calkins MJ, Chan K, Kan YW, Johnson JA (2003) Identification of the NF-E2-related factor-2-dependent genes conferring protection against oxidative stress in primary cortical astrocytes using oligonucleotide microarray analysis. J Biol Chem 278(14):12029-12038. doi:10.1074/jbc.M211558200
66. Li MH, Cha YN, Surh YJ (2006) Peroxynitrite induces HO-1 expression via PI3K/Akt-dependent activation of NF-E2-related factor 2 in PC12 cells. Free Radic Biol Med 41(7):1079-1091. doi:10.1016/j.freeradbiomed.2006.06.010

67. Lieber CS (2004) CYP2E1: from ASH to NASH. Hepatol Res 28(1):1-11

68. Lluis JM, Colell A, Garcia-Ruiz C, Kaplowitz N, FernandezCheca JC (2003) Acetaldehyde impairs mitochondrial glutathione transport in HepG2 cells through endoplasmic reticulum stress. Gastroenterology 124(3):708-724. doi:10.1053/gast. 2003.50089

69. Lu C, Armstrong JS (2007) Role of calcium and cyclophilin D in the regulation of mitochondrial permeabilization induced by glutathione depletion. Biochem Biophys Res Commun 363(3): 572-577. doi:10.1016/j.bbrc.2007.08.196

70. Lu SC (1999) Regulation of hepatic glutathione synthesis: current concepts and controversies. FASEB J 13(10):1169-1183

71. Lu W, Chen Z, Zhang H, Wang Y, Luo Y, Huang P (2012) ZNF143 transcription factor mediates cell survival through upregulation of the GPX1 activity in the mitochondrial respiratory dysfunction. Cell Death Dis 3:e422. doi:10.1038/cddis. 2012.156

72. Lukivskaya O, Zavodnik L, Knas M, Buko V (2006) Antioxidant mechanism of hepatoprotection by ursodeoxycholic acid in experimental alcoholic steatohepatitis. Adv Med Sci 51:54-59

73. Mari M, Bai J, Cederbaum AI (2002) Toxicity by pyruvate in HepG2 cells depleted of glutathione: role of mitochondria. Free Radic Biol Med 32(1):73-83

74. Mari M, Cederbaum AI (2000) CYP2E1 overexpression in HepG2 cells induces glutathione synthesis by transcriptional activation of gamma-glutamylcysteine synthetase. J Biol Chem 275(20):15563-15571. doi:10.1074/jbc.M907022199

75. Mari M, Wu D, Nieto N, Cederbaum AI (2001) CYP2E1dependent toxicity and up-regulation of antioxidant genes. J Biomed Sci 8(1):52-58

76. Masterjohn C, Mah E, Park Y, Pei R, Lee J, Manautou JE, Bruno RS (2013) Acute glutathione depletion induces hepatic methylglyoxal accumulation by impairing its detoxification to D-lactate. Exp Biol Med (Maywood) 238(4):360-369. doi:10. $1177 / 1535370213477987$

77. Mitsuyoshi H, Nakashima T, Sumida Y, Yoh T, Nakajima Y, Ishikawa H, Inaba K, Sakamoto Y, Okanoue T, Kashima K (1999) Ursodeoxycholic acid protects hepatocytes against oxidative injury via induction of antioxidants. Biochem Biophys Res Commun 263(2):537-542. doi:10.1006/bbrc.1999.1403

78. Mohammad MK, Avila D, Zhang J, Barve S, Arteel G, McClain C, Joshi-Barve S (2012) Acrolein cytotoxicity in hepatocytes involves endoplasmic reticulum stress, mitochondrial dysfunction and oxidative stress. Toxicol Appl Pharmacol 265(1): 73-82. doi:10.1016/j.taap.2012.09.021

79. Montet AM, Oliva L, Beauge F, Montet JC (2002) Bile salts modulate chronic ethanol-induced hepatotoxicity. Alcohol Alcohol 37(1):25-29

80. Morimoto M, Hagbjork AL, Wan YJ, Fu PC, Clot P, Albano E, Ingelman-Sundberg M, French SW (1995) Modulation of experimental alcohol-induced liver disease by cytochrome P450 2E1 inhibitors. Hepatology 21(6):1610-1617

81. Nagai H, Matsumaru K, Feng G, Kaplowitz N (2002) Reduced glutathione depletion causes necrosis and sensitization to tumor necrosis factor-alpha-induced apoptosis in cultured mouse hepatocytes. Hepatology 36(1):55-64. doi:10.1053/jhep.2002. 33995

82. Nagelkerke JF, van de Water B, Twiss IM, Zoetewey JP, de Bont HJ, Dogterom P, Mulder GJ (1991) Role of microtubuli in secretion of very-low-density lipoprotein in isolated rat 
hepatocytes: early effects of thiol reagents. Hepatology 14(6): 1259-1268

83. Nieto N, Friedman SL, Cederbaum AI (2002) Stimulation and proliferation of primary rat hepatic stellate cells by cytochrome P450 2E1-derived reactive oxygen species. Hepatology 35(1):62-73. doi:10.1053/jhep.2002.30362

84. Nieto N, Mari M, Cederbaum AI (2003) Cytochrome P450 2E1 responsiveness in the promoter of glutamate-cysteine ligase catalytic subunit. Hepatology 37(1):96-106. doi:10.1053/jhep. 2003.50003

85. Oakley A (2011) Glutathione transferases: a structural perspective. Drug Metab Rev 43(2):138-151. doi:10.3109/03602 532.2011 .558093

86. Oguro T, Hayashi M, Nakajo S, Numazawa S, Yoshida T (1998) The expression of heme oxygenase-1 gene responded to oxidative stress produced by phorone, a glutathione depletor, in the rat liver; the relevance to activation of c-jun n-terminal kinase. J Pharmacol Exp Ther 287(2):773-778

87. Okada K, Shoda J, Taguchi K, Maher JM, Ishizaki K, Inoue Y, Ohtsuki M, Goto N, Takeda K, Utsunomiya H, Oda K, Warabi E, Ishii T, Osaka K, Hyodo I, Yamamoto M (2008) Ursodeoxycholic acid stimulates Nrf2-mediated hepatocellular transport, detoxification, and antioxidative stress systems in mice. Am J Physiol Gastrointest Liver Physiol 295(4):G735-G747. doi:10.1152/ajpgi.90321.2008

88. Okada R, Maeda K, Nishiyama T, Aoyama S, Tozuka Z, Hiratsuka A, Ikeda T, Kusuhara H, Sugiyama Y (2011) Involvement of different human glutathione transferase isoforms in the glutathione conjugation of reactive metabolites of troglitazone. Drug Metab Dispos 39(12):2290-2297. doi:10.1124/dmd.111. 040469

89. Park JH, Jung JH, Yang JY, Kim HS (2013) Olive leaf downregulates the oxidative stress and immune dysregulation in streptozotocin-induced diabetic mice. Nutr Res 33(11):942-951. doi:10.1016/j.nutres.2013.07.011

90. Phimister AJ, Williams KJ, Van Winkle LS, Plopper CG (2005) Consequences of abrupt glutathione depletion in murine Clara cells: ultrastructural and biochemical investigations into the role of glutathione loss in naphthalene cytotoxicity. J Pharmacol Exp Ther 314(2):506-513. doi:10.1124/jpet.105.084533

91. Pires DA, Marques PE, Pereira RV, David BA, Gomides LF, Dias AC, Nunes-Silva A, Pinho V, Cara DC, Vieira LQ, Teixeira MM, Menezes GB (2014) Interleukin-4 deficiency protects mice from acetaminophen-induced liver injury and inflammation by prevention of glutathione depletion. Inflamm Res 63(1):61-69. doi:10.1007/s00011-013-0671-7

92. Plummer JL, Smith BR, Sies H, Bend JR (1981) Chemical depletion of glutathione in vivo. Methods Enzymol 77:50-59

93. Prabakaran D, Ashokkumar N (2013) Protective effect of esculetin on hyperglycemia-mediated oxidative damage in the hepatic and renal tissues of experimental diabetic rats. Biochimie 95(2):366-373. doi:10.1016/j.biochi.2012.10.008

94. Prasath GS, Subramanian SP (2013) Fisetin, a tetra hydroxy flavone recuperates antioxidant status and protects hepatocellular ultrastructure from hyperglycemia mediated oxidative stress in streptozotocin induced experimental diabetes in rats. Food Chem Toxicol 59:249-255. doi:10.1016/j.fct.2013.05.062

95. Quesada-Soriano I, Primavera A, Casas-Solvas JM, Tellez-Sanz R, Baron C, Vargas-Berenguel A, Lo Bello M, Garcia-Fuentes L (2012) Identifying and characterizing binding sites on the irreversible inhibition of human glutathione S-transferase P1-1 by S-thiocarbamoylation. ChemBioChem 13(11):1594-1604. doi:10.1002/cbic.201200210

96. Randle LE, Goldring CE, Benson CA, Metcalfe PN, Kitteringham NR, Park BK, Williams DP (2008) Investigation of the effect of a panel of model hepatotoxins on the Nrf2-Keap1 defence response pathway in CD-1 mice. Toxicology 243(3):249-260. doi:10.1016/j.tox.2007.10.011

97. Raza H (2011) Dual localization of glutathione S-transferase in the cytosol and mitochondria: implications in oxidative stress, toxicity and disease. FEBS J 278(22):4243-4251. doi:10.1111/j. 1742-4658.2011.08358.x

98. Richman PG, Meister A (1975) Regulation of gamma-glutamylcysteine synthetase by nonallosteric feedback inhibition by glutathione. J Biol Chem 250(4):1422-1426

99. Robertson G, Leclercq I, Farrell GC (2001) Nonalcoholic steatosis and steatohepatitis. II. Cytochrome P-450 enzymes and oxidative stress. Am J Physiol Gastrointest Liver Physiol 281(5):G1135-G1139

100. Roman J, Colell A, Blasco C, Caballeria J, Pares A, Rodes J, Fernandez-Checa JC (1999) Differential role of ethanol and acetaldehyde in the induction of oxidative stress in HEP G2 cells: effect on transcription factors AP-1 and NF-kappaB. Hepatology 30(6):1473-1480. doi:10.1002/hep.510300623

101. Ryle PR, Chakraborty J, Thomson AD (1986) The role of the hepatocellular redox state in the hepatic triglyceride accumulation following acute ethanol administration. Biochem Pharmacol 35(18): 3159-3164. doi:10.1155/2013/2313780006-2952(86)90402-8

102. Salama RM, Schaalan MF, Elkoussi AA, Khalifa AE (2013) Potential utility of sodium selenate as an adjunct to metformin in treating type ii diabetes mellitus in rats: a perspective on protein tyrosine phosphatase. Biomed Res Int 2013:231378. doi:10. $1155 / 2013 / 231378$

103. Salaspuro MP, Shaw S, Jayatilleke E, Ross WA, Lieber CS (1981) Attenuation of the ethanol-induced hepatic redox change after chronic alcohol consumption in baboons: metabolic consequences in vivo and in vitro. Hepatology 1(1):33-38

104. Salazar M, Rojo AI, Velasco D, de Sagarra RM, Cuadrado A (2006) Glycogen synthase kinase-3beta inhibits the xenobiotic and antioxidant cell response by direct phosphorylation and nuclear exclusion of the transcription factor Nrf2. J Biol Chem 281(21):14841-14851. doi:10.1074/jbc.M513737200

105. Sekhar KR, Spitz DR, Harris S, Nguyen TT, Meredith MJ, Holt JT, Gius D, Marnett LJ, Summar ML, Freeman ML (2002) Redox-sensitive interaction between KIAA0132 and Nrf2 mediates indomethacin-induced expression of gamma-glutamylcysteine synthetase. Free Radic Biol Med 32(7):650-662

106. Setshedi M, Wands JR, Monte SM (2010) Acetaldehyde adducts in alcoholic liver disease. Oxid Med Cell Longev 3(3):178-185. doi:10.4161/oxim.3.3.12288

107. Shear NH, Malkiewicz IM, Klein D, Koren G, Randor S, Neuman MG (1995) Acetaminophen-induced toxicity to human epidermoid cell line A431 and hepatoblastoma cell line Hep G2, in vitro, is diminished by silymarin. Skin Pharmacol 8(6): 279-291

108. Shinohara M, Ybanez MD, Win S, Than TA, Jain S, Gaarde WA, Han D, Kaplowitz N (2010) Silencing glycogen synthase kinase-3beta inhibits acetaminophen hepatotoxicity and attenuates JNK activation and loss of glutamate cysteine ligase and myeloid cell leukemia sequence 1. J Biol Chem 285(11): 8244-8255. doi:10.1074/jbc.M109.054999

109. Simoni RD, Hill RL, Vaughan M (2002) On glutathione. II. A thermostable oxidation-reduction system (Hopkins FG, Dixon M (1922) J Biol Chem 54 527-563). J Biol Chem 277 (24):e13

110. Tapryal N, Mukhopadhyay C, Mishra MK, Das D, Biswas S, Mukhopadhyay CK (2010) Glutathione synthesis inhibitor butathione sulfoximine regulates ceruloplasmin by dual but opposite mechanism: implication in hepatic iron overload. Free Radic Biol Med 48(11):1492-1500. doi:10.1016/j.freeradbio med.2010.02.029

111. Tekwe CD, Lei J, Yao K, Rezaei R, Li X, Dahanayaka S, Carroll RJ, Meininger CJ, Bazer FW, Wu G (2013) Oral administration 
of interferon tau enhances oxidation of energy substrates and reduces adiposity in Zucker diabetic fatty rats. BioFactors 39(5):552-563. doi:10.1002/biof.1113

112. Thompson JA, Franklin CC (2010) Enhanced glutathione biosynthetic capacity promotes resistance to As3+-induced apoptosis. Toxicol Lett 193(1):33-40. doi:10.1016/j.toxlet.2009.12. 004

113. Tirmenstein MA, Nicholls-Grzemski FA, Zhang JG, Fariss MW (2000) Glutathione depletion and the production of reactive oxygen species in isolated hepatocyte suspensions. Chem Biol Interact 127(3):201-217

114. Traverso N, Menini S, Odetti P, Pronzato MA, Cottalasso D, Marinari UM (1999) Lipoperoxidation in hepatic subcellular compartments of diabetic rats. Free Radic Biol Med 26(5-6): 538-547

115. Uchida K, Shiraishi M, Naito Y, Torii Y, Nakamura Y, Osawa T (1999) Activation of stress signaling pathways by the end product of lipid peroxidation. 4-hydroxy-2-nonenal is a potential inducer of intracellular peroxide production. $\mathrm{J}$ Biol Chem 274(4):2234-2242

116. Vidal K, Breuille D, Serrant P, Denis P, Glomot F, Bechereau F, Papet I (2013) Long-term cysteine fortification impacts cysteine/ glutathione homeostasis and food intake in ageing rats. Eur $\mathbf{J}$ Nutr. doi:10.1007/s00394-013-0600-0

117. Vina J, Estrela JM, Guerri C, Romero FJ (1980) Effect of ethanol on glutathione concentration in isolated hepatocytes. Biochem J 188(2):549-552

118. Wang X, Liu R, Zhang W, Zhang X, Liao N, Wang Z, Li W, Qin X, Hai C (2013) Oleanolic acid improves hepatic insulin resistance via antioxidant, hypolipidemic and anti-inflammatory effects. Mol Cell Endocrinol 376(1-2):70-80. doi:10.1016/j. mce.2013.06.014

119. Watanabe I, Tomita A, Shimizu M, Sugawara M, Yasumo H, Koishi R, Takahashi T, Miyoshi K, Nakamura K, Izumi T, Matsushita Y, Furukawa H, Haruyama H, Koga T (2003) A study to survey susceptible genetic factors responsible for troglitazone-associated hepatotoxicity in Japanese patients with type 2 diabetes mellitus. Clin Pharmacol Ther 73(5):435-455
120. Weltman MD, Farrell GC, Hall P, Ingelman-Sundberg M, Liddle C (1998) Hepatic cytochrome P450 2E1 is increased in patients with nonalcoholic steatohepatitis. Hepatology 27(1): 128-133. doi:10.1002/hep.510270121

121. Willems P, Wanschers BF, Esseling J, Szklarczyk R, Kudla U, Duarte I, Forkink M, Nooteboom M, Swarts H, Gloerich J, Nijtmans L, Koopman W, Huynen MA (2013) BOLA1 is an aerobic protein that prevents mitochondrial morphology changes induced by glutathione depletion. Antioxid Redox Signal 18(2): 129-138. doi:10.1089/ars2011.4253

122. Wu D, Cederbaum AI (1996) Ethanol cytotoxicity to a transfected HepG2 cell line expressing human cytochrome P4502E1. J Biol Chem 271(39):23914-23919

123. Wu D, Cederbaum AI (2001) Removal of glutathione produces apoptosis and necrosis in HepG2 cells overexpressing CYP2E1. Alcohol Clin Exp Res 25(4):619-628

124. Wu D, Wang X, Zhou R, Yang L, Cederbaum AI (2012) Alcohol steatosis and cytotoxicity: the role of cytochrome P4502E1 and autophagy. Free Radic Biol Med 53(6):1346-1357. doi:10.1016/j. freeradbiomed.2012.07.005

125. Wu KC, Liu J, Klaassen CD (2012) Role of Nrf2 in preventing ethanol-induced oxidative stress and lipid accumulation. Toxicol Appl Pharmacol 262(3):321-329. doi:10.1016/j.taap.2012.05. 010

126. Yao WB, Zhao YQ, Abe T, Ohta J, Ubuka T (1994) Effect of $N$ acetylcysteine administration on cysteine and glutathione contents in liver and kidney and in perfused liver of intact and diethyl maleate-treated rats. Amino Acids 7(3):255-266. doi:10. 1007/BF00807701

127. Zhang H, Shih A, Rinna A, Forman HJ (2009) Resveratrol and 4-hydroxynonenal act in concert to increase glutamate cysteine ligase expression and glutathione in human bronchial epithelial cells. Arch Biochem Biophys 481(1):110-115. doi:10.1016/j. abb.2008.10.020

128. Zhuge J, Cederbaum AI (2006) Increased toxicity by transforming growth factor-beta 1 in liver cells overexpressing CYP2E1. Free Radic Biol Med 41(7):1100-1112. doi:10.1016/j. freeradbiomed.2006.06.017 